\title{
Calcium and iron intakes of adolescents in Malaysia and their relationships with body mass index (BMI): Findings from the Adolescent Nutrition Survey 2017
}

\author{
Syafinaz Mohd Sallehuddin ${ }^{1}$, Ruzita Abd. Talib ${ }^{2 *}$, Ruhaya Salleh ${ }^{1}$, Rashidah \\ Ambak $^{1}$, Munawara Pardi ${ }^{1}$, Nur Shahida Abdul Aziz ${ }^{1}$, Norazizah Ibrahim Wong ${ }^{3}$ \\ \& Mohd Azahadi Omar ${ }^{3}$
}

${ }^{1}$ Institute for Public Health, National Institute of Health, Ministry of Health Malaysia, Setia Alam, 40170 Shah Alam Selangor Malaysia; ${ }^{2}$ Nutritional Sciences Programme \& Centre for Community Health Studies (ReaCH), Faculty of Health Sciences, Universiti Kebangsaan Malaysia, 50300 Kuala Lumpur, Malaysia; ${ }^{3}$ Sector of Biostatistics and Data Repository, National Institute of Health, Ministry of Health Malaysia

\begin{abstract}
Introduction: Adolescent health is a priority considering they represent the future generation. Data from the Adolescent Nutrition Survey 2017 were analysed to determine the prevalence of micronutrient inadequacy, particularly calcium and iron, and the relationship with body mass index (BMI) among Malaysian secondary school students. Methods: This cross-sectional study included students aged 13 to 17 years old studying at public and private schools. Twenty-four hours dietary recall via face-to-face interview was conducted by trained nutritionists to obtain data on dietary intake. For nutritional status, BMI-for-age $\mathrm{Z}$-score (BAZ) was analysed using WHO Anthroplus software. Results: From 999 respondents, 449 were boys and 550 were girls. Overall findings indicated that both boys and girls had inadequate intakes of calcium and iron in their daily diet. Mean intakes of calcium $(695.7 \pm 463.2 \mathrm{mg} /$ day) and iron $(23.4 \pm 21.0 \mathrm{mg} /$ day $)$ were higher among boys aged 16 to 17 years old. Mean intake of iron were higher among the older age groups. Majority of the respondents (boys: 94\%; girls: 97\%) did not meet the recommended nutrient intake (RNI) for calcium and more than half (boys: 50\%; girl: $80 \%$ ) did not achieve the RNI for iron. Current findings also found significant positive but weak correlations between calcium $(r=0.112, p=0.001)$ and iron $(r=0.084, p=0.008)$ intakes with BMI-for-age. Conclusion: BMI-for-age was related to calcium and iron intakes among secondary school students in Malaysia. Thus, intervention strategies should focus on early screening and nutrition education on food choices of high calcium and high iron contents, including iron supplementation programmes, if needed.
\end{abstract}

Keywords: adolescents, calcium, iron, intake, Malaysia

\section{INTRODUCTION}

Adolescence is the transition period from childhood to adulthood with immense growth in opportunities, trials and challenges. The World Health Organization (WHO) (2014) defines an adolescent as any person between the ages of 10 and 19 years. Due to their rapid biological and psychological changes, adolescents are frequently perceived as a nutritionally vulnerable group (WHO, 2014). Adolescent health is

\footnotetext{
*Corresponding author: Ruzita Abd. Talib

Nutritional Sciences Programme \& Centre for Community Health Studies (ReaCH),

Faculty of Health Sciences, Universiti Kebangsaan Malaysia, 50300 Kuala Lumpur, Malaysia

Correspondence: rzt@ukm.edu.my

doi: https: / / doi.org/10.31246/mjn-2020-0054
} 
to be prioritised as they are the future generation of the world and their health status is important for the well-being of each community (Patton et al., 2016).

Calcium is important for bone health. Due to intensive bone and muscular development, there is an increased need for calcium among adolescents (Mouratidou et al., 2013). Apart from bone and muscular development, hormonal changes and growth during puberty also encourage more mineral use, thus requiring higher intake of minerals such as calcium (Mesias et al., 2013). However, most children and adolescents throughout the world are unable to meet the recommended calcium intake.

Another mineral essential for growth and development during adolescence is iron. Iron stored during growth is important for haemoglobin and blood circulation. Among boys, adequate intake of iron is necessary to sustain the rapid gain in muscle mass and blood volume. Although girls gain muscle and blood volume slower than boys, adolescent girls remain in need of high iron intake to support menstrual losses as well as for growth. Deficiency in iron among children and adolescents can lead to anaemia, which can cause impairment in physical growth, mental and motor development, as well as learning capacity (Lassi et al., 2017). Iron deficiency among adolescents is recognised as a significant nutritional problem worldwide, across both developing and developed nations (Finkelstein et al., 2018).

Food intake among adolescents in many developing countries nowadays comprises primarily of foods high in fat, sugar and salt content such as fast foods, processed foods, sweets and sugar-sweetened drinks. Conversely, their diet is frequently low in fibre-rich foods including whole grains, fruits and vegetables or legumes (Hassapidou et al., 2006). In a past study involving 165 adolescents between 12-19 years old from a rural community in Sabah, Malaysia (Foo et al., 2004), almost 98\% of subjects did not meet the Malaysian Recommended Dietary Allowance (RDA) level (<9mg/day) for dietary iron intake (NCCFN, 2017). Another study in Malaysia also revealed that $80 \%$ and possibly more children achieved the Recommended Nutrient Intake (RNI) for almost all nutrients, except for calcium and vitamin D (Poh et al., 2013). About 794 diet histories from adolescents aged 13 years old were analysed in The MyHEART cohort study (Majid et al., 2016) in Peninsular Malaysia, which was aimed to investigate the dietary intakes of Malaysian adolescents. The study showed that both males and females consumed inadequate intakes of energy, vitamin $\mathrm{D}$, and calcium. It also showed that females consumed inadequate levels of iron (<100\%) (Majid et al., 2016).

Healthy eating habits during adolescence are the foundation for optimum health in adulthood. Previous findings have reported an association between body weight and iron deficiency among adolescents (Hutchinson, 2016; Aigner et al., 2014, Moayer et al., 2006). Meanwhile, another study found no significant association between calcium and body weight management (Shapses, Heshka \& Heymsfield, 2004).

Therefore, this study was undertaken to determine the prevalence of inadequate micronutrient intake, particularly calcium and iron intakes, among Malaysian adolescents, and to investigate the relationships between calcium and iron intakes with body mass index (BMI) using data from the Adolescent Nutrition Survey (ANS) (IPH, 2017).

\section{MATERIALS AND METHODS}

\section{Study setting and sample size}

The optimum sample size required for the ANS 2017 was 30,496 respondents based on the single proportion formula 
and stratification of the 16 states in Malaysia (including Federal Territory of Kuala Lumpur, Putrajaya, and Labuan) (IPH, 2017). Based on students' enrolment data, as well as the schools registered with the Ministry of Education Malaysia, there were 7,926 primary schools and 2,688 secondary schools were included in the sampling frame. The schools were inclusive of national schools, vernacular schools, and private schools. From this sampling frame, 311 schools were selected based on random selection to participate in ANS 2017.

\section{Study design and participants}

The Adolescent Nutrition Survey was a cross-sectional study involved adolescents aged 10 to 17 years old, attending public and private schools in Malaysia. However, only data of respondents aged 13 to 17 years old were analysed for this manuscript as this age group was more likely to have low calcium and iron consumption (IPH, 2017). Data collection commenced from 26th March to 3rd May 2017 (IPH, 2017).

\section{Ethics approval and consent to participate}

Ethical approval was obtained from the Ministry of Health, Research and Ethics Committee (NMRR No: NMRR-16-69830042). Approval was also granted by the Ministry of Education officials at the State and District levels, as well as from the respective selected schools.

\section{Sampling procedure}

A multistage stratified cluster sampling was used to ensure a nationwide representative sample of adolescents aged 13 to 17 years old. Students were selected based on random sampling method and invited to participate in the survey. Informed consent from the students involved and parental consent was obtained before the survey was conducted. However, from the 311 qualified schools participated in this survey, only 999 respondents who completed dietary recall and sociodemographic characteristics were being analysed.

\section{Anthropometric measurements}

BMI-for-age $z$-scores (BAZ) of adolescents were identified based on the WHO Growth Reference 2007 (WHO, 2007). Trained research assistants conducted the anthropometric measurements. Weight and height measurements were obtained based on standard methods using a SECA weighing scale (SECA Clara 803, Germany) and a SECA stadiometer (SECA 217, Germany), recorded to the nearest $0.5 \mathrm{~kg}$ and $0.1 \mathrm{~cm}$, respectively. The measurements were taken twice and average readings were calculated and recorded. Weight, height and age of children were processed using the WHO AnthroPlus software to calculate standard scores (z-scores) for BMI-forage, which is an indicator for thinness.

\section{Assessment of dietary intake}

Dietary assessment in the Adolescent Nutrition Survey 2017 involved habitual food intake assessment using food frequency questionnaire and 24-hour dietary recall. However, this study only reports the outcomes from the 24-hour dietary recalls. The assessment of dietary intake was done by trained nutritionists using a single 24-hour dietary recall via face-to-face interview in the national language (Hassapidou et al., 2006, Mouratidou et al., 2013). Data were gathered using a standard form with the aid of food album and explorative questions to allow respondents to recall consumed foods and beverages. Nutrient intakes were determined from the diet recalls using the Nutritionist Pro software (Axxya Systems, Stafford, TX USA), based principally on the Malaysian Food Composition (Tee et al., 1997). Mean intakes of calcium and iron were derived from the analysis. However, sources of calcium and iron from foods 
were not determined in this study, and iron intake was not differentiated between haem and non-haem iron.

\section{Data processing and analysis}

Data were analysed using SPSS version 21. Sample weight was calculated based on every student's dietary recall record and was adjusted for varying probabilities of selection, as well as for study non-responses. Complex samples analysis was performed in the statistical analysis and was conducted at $95 \%$ confidence interval. For analysis purposes, respondents were assigned according to age groups based on RNI for Malaysia 2017 (NCCFN 2017). Thus, data of calcium and iron intakes were interpreted based on these age group classifications.

\section{RESULTS}

\section{Sociodemographic characteristics}

Sociodemographic characteristics of the adolescents are shown in Table 1. Overall, 999 respondents completed data collection for dietary intake and sociodemographic characteristics. A large percentage of the respondents was from the age group of 15 to 17 years old, with slightly higher proportion of female $(55.1 \%)$ students, from urban areas (53.8\%), and Malays (66.6\%).

\section{Comparison of calcium and iron intakes by sex, strata and ethnicity} In Table 2, from Mann-Whitney $U$ test and Kruskal-Wallis test, there were statistically significant differences for calcium and iron intakes

Table 1. Socio-demographic characteristics of subjects

\begin{tabular}{|c|c|c|c|}
\hline \multirow[b]{2}{*}{ Characteristics } & \multicolumn{2}{|c|}{ Age group } & \multirow[b]{2}{*}{$\begin{array}{c}\text { Total population } \\
n(\%)\end{array}$} \\
\hline & $\begin{array}{c}\text { 13-14 years } \\
n(\%)\end{array}$ & $\begin{array}{c}\text { 15- } 17 \text { years } \\
n(\%)\end{array}$ & \\
\hline \multicolumn{4}{|l|}{ Sex } \\
\hline Boys & $190(42.3)$ & $259(57.7)$ & 449 (44.9) \\
\hline Girls & $236(42.9)$ & $314(57.1)$ & $550(55.1)$ \\
\hline \multicolumn{4}{|l|}{ Strata } \\
\hline Urban & $223(41.5)$ & 314 (58.5) & 537 (53.8) \\
\hline Rural & 203 (43.9) & $259(56.1)$ & $462(46.2)$ \\
\hline \multicolumn{4}{|l|}{ Ethnicity } \\
\hline Malay & 291 (43.8) & 374 (56.2) & 665 (66.6) \\
\hline Chinese & $51 \quad(36.2)$ & 90 (63.8) & 141 (14.1) \\
\hline Indian & $21(48.8)$ & $22(51.2)$ & 43 ( 4.3) \\
\hline Others & $55(40.4)$ & 81 (59.6) & $136(13.6)$ \\
\hline \multicolumn{4}{|l|}{ Bumiputeras } \\
\hline Others & $8(57.1)$ & 6 (42.9) & $14(1.4)$ \\
\hline \multicolumn{4}{|l|}{ BMI categories } \\
\hline Thinness & 27 (43.5) & 35 (56.5) & $62(6.2)$ \\
\hline Normal & $303(40.7)$ & 442 (59.3) & 745 (74.6) \\
\hline Overweight & 61 (48.6) & 59 (49.2) & $120(12.0)$ \\
\hline Obese & $35(48.6)$ & 37 (51.4) & $72(7.2)$ \\
\hline
\end{tabular}




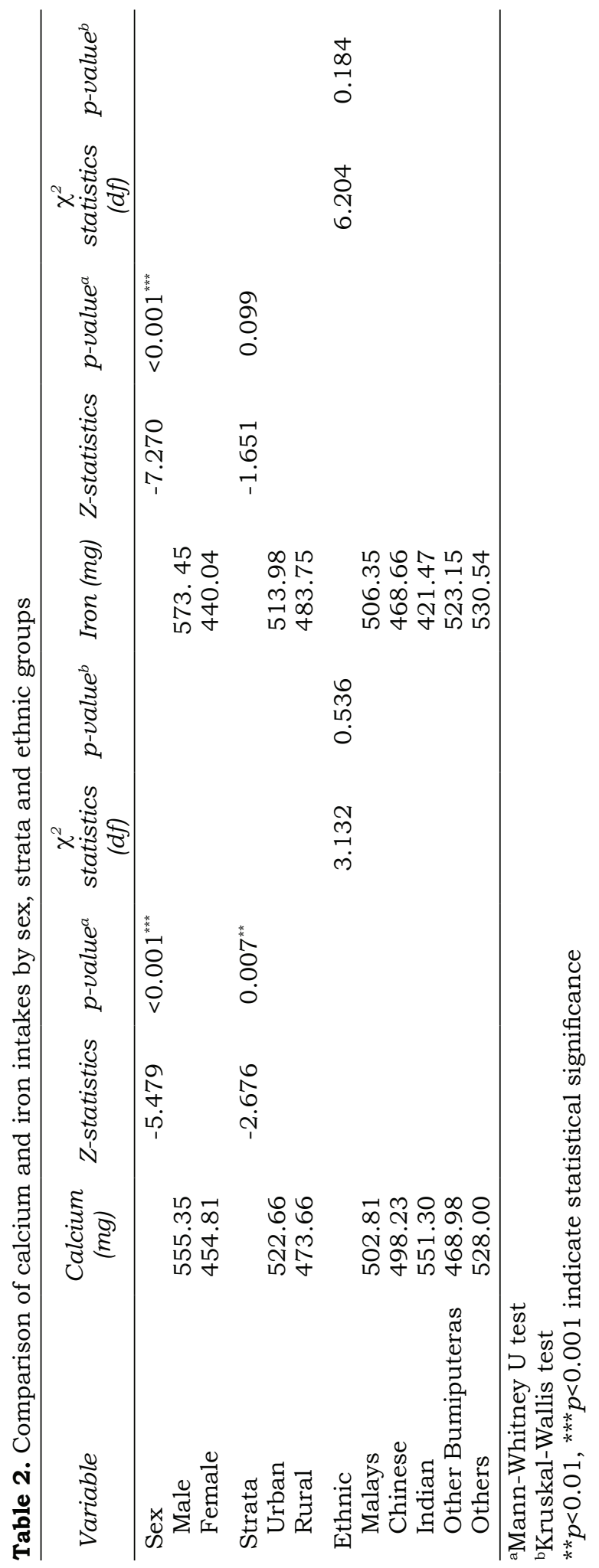


Table 3. Percentage of adolescents according to RNI achievements in calcium intake and iron intake

\begin{tabular}{lccccc}
\hline Gender & $\begin{array}{c}\text { Age group } \\
\text { (years old })\end{array}$ & \multicolumn{2}{c}{$\begin{array}{c}\text { Calcium } \\
n(\%)\end{array}$} & \multicolumn{2}{c}{$\begin{array}{c}\text { Iron } \\
(\%)\end{array}$} \\
\cline { 3 - 6 } & & $\begin{array}{c}\text { Did not achieve } \\
\text { RNI } \\
n(\%)\end{array}$ & $\begin{array}{c}\text { Achieved RNI } \\
n(\%)\end{array}$ & $\begin{array}{c}\text { Did not achieve } \\
\text { RNI } \\
n(\%)\end{array}$ & $\begin{array}{c}\text { Achieved RNI } \\
n(\%)\end{array}$ \\
\hline Boys & $13-14$ & $183(96.3)$ & $7(3.7)$ & $85(44.7)$ & $105(55.3)$ \\
& $15-17$ & $243(93.8)$ & $16(6.2)$ & $139(53.7)$ & $120(46.3)$ \\
Girls & $13-14$ & $232(98.3)$ & $4(1.7)$ & $123(52.1)$ & $113(47.9)$ \\
& $15-17$ & $305(97.1)$ & $9(2.9)$ & $294(93.6)$ & $20(6.4)$ \\
\hline
\end{tabular}

between sex and strata. However, there was no statistically significant difference in calcium intake $\left(\chi^{2}=3.13, p=0.536\right)$ and iron intake $\left(\chi^{2}=6.20, p=0.184\right)$ between ethnic groups.

\section{Proportion of adolescents meeting the RNI}

Table 3 outlines the percentage of adolescents achieving the RNI for calcium and iron intakes in a day. Overall, most respondents did not achieve the RNI for calcium intake and more than half of them did not reach the RNI for iron intake. The results showed that $96.3 \%$ boys and $98.3 \%$ girls aged 13 to 14 years old did not achieve the RNI for calcium, respectively; while $93.8 \%$ boys and $97.1 \%$ girls aged 15 to 17 years old did not achieve the RNI for calcium. For iron intake, $44.7 \%$ boys and $53.5 \%$ girls aged 13 to 14 years old did not achieve the RNI for iron; while $52.1 \%$ boys and 93.6\% girls aged 15 to 17 years old did not achieve the RNI for iron. Besides, this study also revealed that the proportion of girls who failed to achieve the RNI for both calcium and iron intakes were higher than boys.

\section{Correlation between calcium and iron with BMI-for-age}

Although most respondents did not meet the RNI for calcium and iron intakes, this study found a significant, positive but weak correlation between calcium $(r=0.112, p=0.001)$ and iron $(r=0.084$, $p=0.008$ ) intakes with BMI-for-age as presented in Table 4.

\section{DISCUSSION}

The present study highlighted the inadequacy of calcium and iron intakes among Malaysian adolescents. Despite rapid socio-economic growth, Malaysia faces the double burden of malnutrition (Ihab et al., 2013), with low intakes of these two nutrients among the adolescents. Calcium need increases

Table 4. Correlations between calcium and iron intakes with BMI-for-age $z$-scores

\begin{tabular}{lcc}
\hline \multirow{2}{*}{ Mineral } & \multicolumn{3}{c}{ BMI-for-age z-scores } \\
\cline { 2 - 3 } & $r$ & $p^{\dagger}$ \\
\hline Calcium (mg/day) & 0.112 & 0.001 \\
Iron (mg/day) & 0.084 & $0.008^{* *}$ \\
\hline
\end{tabular}

${ }^{\dagger}$ Pearson Correlation test

** $p<0.01$ indicates statistical significance 
with age due to intensive bone and muscular progress (Mesias et al., 2011). It is therefore crucial to ensure sufficient calcium intake throughout the growing age to ensure optimum peak bone mass and to prevent osteoporosis in adulthood (Mouratidou et al., 2013). Unfortunately, findings from the current study showed that more than $90 \%$ of adolescents did not meet the calcium RNI, thereby presenting a public health risk.

The findings from this study are consistent with earlier reports (Im et al., 2014; de Assumpcao et al., 2016), which revealed that most children and adolescents in Korea and in Iran failed to meet the recommended calcium intake (1300 mg/day) (WHO, 2006). Therefore, it is encouraged to provide a diet with adequate nutrient composition and sufficient calcium allowance for maximum bone mass growth (Im et al., 2014).

Findings from this study also showed that adolescents consumed insufficient iron. As compared with this study, findings from of an earlier local study by Foo et al., (2004) among rural communities in Sabah, Malaysia showed unsatisfactory dietary iron intake among adolescents aged 12 to 19 years, with $98 \%$ of subjects not meeting the Malaysian RDA level for iron [14.4 $\mu \mathrm{mol} / \mathrm{L}$ (male), $10.3 \mu \mathrm{mol} / \mathrm{L}$ (female)]. In another local study, about $91 \%$ of female subjects had dietary iron intake below two-thirds of the RDA level compared to a smaller proportion among male adolescents (68\%) (Foo et al., 2004). Another finding from this current study was the lower mean calcium intake among adolescents living in the rural area, which is in line with another local study that suggested it was a common occurrence in rural areas (Foo et al., 2004).

This is probably due to females having menses and not eating appropriately according to their requirements. Mesias et al. (2013) justified that adolescence is a period of time when iron needs are optimised in line with increases in blood volume and growth of muscle mass. Hence, lack of iron intake may lead to iron deficiency and adversely affect body physiology. Adverse effects related to iron deficiency are more likely to occur especially among female adolescents, athletes, and those who limit their meat intake (Mesias et al., 2013). The current findings also showed that there were significant differences in calcium and iron intakes between boys and girls. These findings are similar with a study from China that also showed significant gender differences (Wang et al., 2017).

There is a possibility of calcium absorption being interfered by high protein intake, as a previous finding mentioned that adequacy of high-quality protein intake may impact calcium absorption (Calvez et al., 2012). Low bioavailability of iron might also be related to the intake of vitamin C. However, a study from the Kansas, USA mentioned most epidemiology studies were unable to show an association between vitamin $\mathrm{C}$ intake and iron absorption status (Cook \& Reddy, 2001). Furthermore, iron deficiency anaemia is known as a significant factor contributing to micronutrient malnutrition in Malaysia (Teegarden, 2003).

This study showed a positive correlation between calcium and iron intakes with BMI -for-age $z$-score. This indicates the contribution of these minerals towards BMI. Although there is no evidence available to support the association between calcium intake and BMI, dietary calcium seems to be related to energy metabolism, where it is suggested to play a substantial role in contributing and reducing the incidence of obesity (Teegarden, 2003). However, this may be due to the effect of nutrient density, that might be influenced by total energy intake rather than the micronutrient itself. No local study has revealed any association between BMI and iron intake. Nevertheless, a foreign study which took place in a rural 
area in North West Ethiopia among adolescent schoolgirls, found that BMIfor-age $[A O R=3.2 ; 95 \% \mathrm{CI} \quad(1.43-7.05)]$ was among the predictors of anaemia (Mengistu et al., 2019).

Adolescents should be trained, supported and encouraged to eat healthy foods and a balanced diet, as well as to practise a healthy lifestyle to promote optimal calcium consumption and iron absorption. Findings from the current study indicate the importance of nutrition education and promotion in school environment or via school programmes to ensure that messages on balanced and healthy diet reach the adolescent group. Nutrition education and promotion on high calcium and high iron foods can enhance the knowledge and awareness on healthy nutrition practices among adolescents (Xie et al., 2003).

The present study is among the few large-scale population-based studies that have been conducted in Malaysia. The data represent all students attending schools in Malaysia and the outcomes can be used to enhance health programmes, focusing particularly on nutrition, for adolescents.

\section{Limitation of the study}

This study did not encompass major food sources of calcium and iron intakes of adolescents. Besides, factors contributing to the inadequacy of calcium and iron intakes among adolescents were not determined in this study. Therefore, this information should be included in future studies to help Malaysian adolescents achieve calcium and iron recommendations.

\section{CONCLUSION}

The findings confirmed that Malaysian adolescents have inadequate calcium and iron intakes. The percentage of adolescents meeting the RNI for both calcium and iron was alarmingly high.
There were significant associations between calcium and iron intakes with BMI. These results indicate that messages promoting balanced nutrition are not reaching the adolescents. The level of knowledge and awareness on good nutrition should be emphasised. Thus, intervention strategies should focus on early screening and nutrition education on food sources of high calcium and high iron contents, including iron supplementation, if needed.

\section{Acknowledgements}

We would like to thank the Director General of Health Malaysia for his permission to publish this article. We also thank our study participants, data collectors and supervisors, who were involved in this study.

\section{Authors' contributions}

SMS, involved in collating the data, preparation of the draft manuscript, and reviewed the manuscript; RAT was responsible for the concept of the project development, prepared the draft of the manuscript, involved with interpretation of data analysis, and reviewed the manuscript; RS, principal investigator, conceptualised, responsible for the project development, supervised the project's progress, and reviewed the manuscript; RA, MP, NSAA assisted in the preparation of the manuscript, reviewed and approved the final manuscript. NIW and MAO conducted the data analysis and interpretation of the data, and reviewed the manuscript.

\section{Availability of data and materials}

Data will be available upon request from the corresponding author.

\section{Conflict of interests}

The authors declare that they have no competing interests.

\section{References}

Aigner E, Feldman A \& Datz C (2014). Obesity as an emerging risk factor for iron deficiency. Nutrients 6(9):3587-3600.

Calvez J, Poupin N, Chesneau C, Lassale C \& Tome D (2012). Protein Intake, calcium balance and health consequences. Eur J Clin Nutr 66:281295.

Cook JD \& Reddy MB (2001). Effect of ascorbic acid intake on nonheme-iron absorption from a complete diet. Am J Clin Nutr 73(1):93-8. 
de Assumpção D, Dias MR, de Azevedo Barros MB, Fisberg RM \& de Azevedo Barros Filho A (2016). Calcium intake by adolescents: a population-based health survey. $J$ Pediatr (VersãoemPortuguês) 92(3):251-9.

Finkelstein JL, Herman HS, Guetterman HM, Peña-Rosas JP \& Mehta S (2018). Daily iron supplementation for prevention or treatment of iron deficiency anaemia in infants, children, and adolescents. Cochrane Database Syst Rev 2018(12):CD013227

Foo LH, Khor GL, Tee ES \& Dhanaraj P (2004). Determinants of iron status in Malaysian adolescents from a rural community. Int J Food Sci Nutr 55(6):517-25.

Foo LH, Khor G, Tee E \& Prabakaran D (2004). Iron status and dietary iron intake of adolescents from a rural community in Sabah, Malaysia. Asia Pac J Clin Nutr 131:48-55.

Hassapidou M, Fotiadou E, Maglara E \& Papadopoulou SK (2006). Energy intake, diet composition, energy expenditure, and body fatness of adolescents in northern Greece. Obesity 14(5):855-62.

Hutchinson C (2016). A review of iron studies in overweight and obese children and adolescents: a double burden in the young? Eur J Nutr 55(7):2179-97.

Ihab AN, Rohana AJ, Manan WW, Suriati WW, Zalilah MS \& Rusli AM (2013). The coexistence of dual form of malnutrition in a sample of rural Malaysia. Int J Prev Med 4(6):690.

Im JG, Kim SH, Lee GY, Joung H \& Park MJ (2014). Inadequate calcium intake is highly prevalent in Korean children and adolescents: The Korea National Health and Nutrition Examination Survey (KNHANES) 2007-2010. Public Health Nutr 17(11):2489-95.

IPH (2017). National Health and Morbidity Survey (NHMS) 2017: Adolescent Nutrition Survey 2017. Institute for Public Health, Malaysia

Lassi Z, Moin A \& Bhutta Z (2017). Nutrition in Middle Childhood and Adolescence. In D Bundy, N de Silva, S Horton, DT Jamison \& G Patton (eds). Disease Control Priorities (third edition) (Volume 8): Child and Adolescent Health and Development. Washington, DC: World Bank.

Majid HA, Ramli L, Ying SP, Su TT, Jalaludin MY \& Mohsein NA (2016). Dietary intake among adolescents in a middle-income country: An outcome from the Malaysian health and adolescents longitudinal research team study (the MyHeARTs Study). PloS one 11(5):e0155447.
Mesias M, Seiquer I \& Navarro MP (2011). Calcium nutrition in adolescence. Crit Rev Food Sci Nutr 51(3):195-209.

Mesías M, Seiquer I \& Navarro MP (2013). Iron nutrition in adolescence. Crit Rev Food Sci Nutr 53(11):1226-37.

Mengistu G, Azage M \& Gutema H (2019). Iron deficiency anemia among in-school adolescent girls in rural area of Bahir Dar City Administration, North West Ethiopia. Anemia 2019.

Moayeri H, Bidad K, Zadhoush S, Gholami N \& Anari S (2006). Increasing prevalence of iron deficiency in overweight and obese children and adolescents (Tehran Adolescent Obesity Study). Eur J Paediatr 165(11):813-814.

Mouratidou T, Vicente-Rodriguez G, GraciaMarco L, Huybrechts I, Sioen I, Widhalm K, Valtueña J, González-Gross M, Moreno LA \& HELENA Study Group (2013). Associations of dietary calcium, vitamin $\mathrm{D}$, milk intakes, and 25-hydroxyvitamin D with bone mass in Spanish adolescents: the HELENA Study. $J$ Clin Densitom 16(1):110-7.

NCCFN (2017). Recommended Nutrient Intake for Malaysia. A report of the technical working group on nutritional guidelines. National Coordinating Committee on Food and Nutrition, Ministry of Health Malaysia.

Patton GC, Sawyer SM, Santelli JS, Ross DA, Afifi R, Allen NB, Arora M, Azzopardi P, Baldwin W, Bonell C \& Kakuma R (2016). Our future: A Lancet commission on adolescent health and wellbeing. The Lancet 387(10036):2423-78.

Poh BK, Ng BK, Haslinda MD, Shanita SN, Wong JE, Budin SB, Ruzita AT, Ng LO, Khouw I Norimah AK (2013). Nutritional status and dietary intakes of children aged 6 months to 12 years: findings of the Nutrition Survey of Malaysian Children (SEANUTS Malaysia). Br J Nutr 110(S3):S21-35.

Shapses SA, Heshka S \& Heymsfield SB (2004). Effect of calcium supplementation on weight and fat loss in women. J Clin Endocrinol Metab 89(2):632-7.

Teegarden D (2003). Calcium intake and reduction in weight or fat mass. J Nutr 133(1):249S-51S.

Tee E, Ismail M, Nasir AM \& Khatijah I (1997). Nutrient Composition of Malaysian Foods: Malaysian Food Composition Database Programme $4^{\text {th }}$ Edition. Institute for Medical Research, Kuala Lumpur.

Wang H, Wang D, Ouyang Y, Huang F, Ding G \& Zhang B (2017). Do Chinese children get enough micronutrients? Nutrients 9(4):397 
WHO (2006). Adolescent Nutrition: A Review of the Situation in Selected South-East Asian Countries. World Health Organization Regional Office for South-East Asia, New Delhi https:/ / doi.org/10.3126/hprospect.v10i0.5656

WHO (2007). WHO child growth standards: head circumference-for-age, arm circumference-forage, triceps skinfold-for-age and subscapular Skinfold-for-age: methods and development. World Health Organization
WHO (2014). Recognizing adolescence. From http://apps.who.int/adolescent/second decade/section 2 / page 1 / recognizingadolescence.html [Retrieved June 5 2021]

Xie B, Gilliland FD, Li YF \& Rockett HR (2003). Effects of ethnicity, family income, and education on dietary intake among adolescents. Prev Med 36(1):30-40. 